\title{
Intensive insulin therapy in clinical practice
}

\author{
P.D. H ome
}

Newcastle Diabetes Services, University of Newcastle upon Tyne, UK

Summary Achieving optimal blood glucose control, without an unacceptable rate of hypoglycaemia or unacceptable restrictions on lifestyle, is not simple with presently available insulin preparations and monitoring tools. There is considerable evidence that achieved control is relatively independent of the means or frequency of insulin delivery provided at least two injections per day are used, probably due to a combination of the unphysiological nature of insulin absorption profiles, the poor reproducibility of insulin absorption in any individual, and the erratic nature of normal human behaviour. Accordingly the appropriate use of insulin to obtain good metabolic control requires the continued and informed expertise of both patient and advising professional, but also attention from both to self-motivation in order to make the desired lifestyle changes possible. Newer approaches to insulin delivery will continue to demand a high level of understanding and expertise to make them effective, until such time as automatic minute-to-minute control of insulin delivery can be restored. [Diabetologia (1997) 40: S 83-S 87]

Keywords Diabetes mellitus, insulin therapy.
The era of intensive insulin therapy may be said to have been ushered in with the advent of continuous subcutaneous insulin therapy in the late 1970s [1,2], although there are anecdotal reports of individuals, particularly physicians, applying the principles of tight blood glucose control to their own diabetes from the $1920 \mathrm{~s}$ onwards. Indeed the strict diet and multiple injection therapy of the pre-protamine insulin era (before 1940) is known to have been associated with a low incidence of later microvascular complications [3]. The lamentable state of insulin therapy in later decades in many places was illustrated by the regimens already used in some of the patients selected for transfer to insulin infusion pumps, once daily insulin delivery of a variety of formulations being common [2]. Nevertheless it will be part of the thesis of this paper that insulin regimens themselves are, up to a point, not a major component of the success of intensive insulin therapy. It is worth noting

Corresponding author: Professor Philip Home, Department of Medicine, Framlington Place, Newcastle upon Tyne, NE2 $4 \mathrm{HH}, \mathrm{UK}$ that the late 1970 s also saw the introduction of blood glucose self monitoring, and glycated haemoglobin estimation, as well as the more general adoption of patient education programmes [4-7]. These tools, and the change in attitude of the professionals who adopted them, were perhaps more important than choice of insulin regimen in achieving improved blood glucose control.

In 1979, Turner and colleagues [8] challenged the assumption that insulin pump therapy was necessary for the attainment of 'near-normoglycaemia'. As a result a series of studies addressed the question of whether multiple injection therapy had the same potential as continuous subcutaneous insulin infusion for improving blood glucose control [9-11]. In designing these studies the authors adopted to a greater or lesser degree some of the principles that have since become enshrined as components of intensive therapy, in particular as applied to the various studies of the effect of tight control on the evolution of microvascular complications. Some of these components of intensive therapy, and in particular blood glucose selfmonitoring, were subjected to clinical trial at around 
the same time [12]. However, many aspects of intensive therapy remain untested, or rather the extent to which they need to be applied to achieve a useful clinical outcome remains untested.

The confirmation by the Diabetes Control and Complications Trial (DCCT) [13] of the results of earlier studies of the effects of intensive therapy on microvascular complications has reawakened interest in how, and to what extent, intensive insulin therapy can be made available to the majority of people with insulin-dependent diabetes $[13,15]$. The present paper therefore examines:

- what are the components of intensive insulin therapy;

- what components are important, and what components less contributory;

- what can be achieved at what cost in routine clinical practice.

\section{Components of intensive insulin therapy}

In the Miami study published in 1982 [9], a small group $(n=10)$ of people with insulin-dependent diabetes was managed by two doctors (research fellows) working most of their time on the study. Prior to randomization (to pump or multiple injection therapy) the patients had the benefit of a course of re-education about diabetes, dietary principles, and self-monitoring and its aims, and were taught to adjust insulin doses individually on the basis of self-test results. This required frequent self-monitoring to make it effective, as a rule 4-7 times a day, and was supported by telephone advice from the study team. Indeed the patients were telephoned frequently by the doctors, and in addition attended the diabetes clinic at 1-2 week intervals (Table 1). Interestingly, the main gain to improvement of blood glucose control occurred before randomization of the patients to multiple injection therapy or continuous subcutaneous insulin infusion, that is before any change was made in insulin regimen.

That intensity of management has not been achieved or attempted in any subsequent study, although a similar programme was an aim of the intensive arm of the DCCT $[13,16]$. It should be remembered that the aim of this latter study was to establish the benefit of good blood glucose control, and not whether such benefit could be obtained in regular clinical practice. Nevertheless, the results of the study relate, in a strict scientific sense, to the effects of intensive versus less intensive diabetes management and not to better blood glucose control itself. As a result it does not follow that the application of the principles espoused by the DCCT represents the most appropriate or cost-effective practice to be used in routine clinical care. Indeed, given the excess costs of intensive therapy in the DCCT, it is almost certainly
Table 1. Methods of intensity of management during the Miami study [9] of continuous subcutaneous insulin infusion versus a multiple injection regimen

Re-education course

Self-monitoring of blood glucose (4-7 times daily)

Adjustment of insulin doses to meet targets

Supplemental insulin injections

Telephone contact (1-7 times a week)

Group hospitalization and out-patient visits

Family counselling

Clinic visits every 1-2 weeks

clinically inappropriate to apply all its techniques at the same intensity in normal health care. Additionally the incentive of being a member of such a study will be missing in normal life with diabetes.

\section{Insulin regimens and intensive therapy}

The very term 'intensive insulin therapy' carries with it the subconscious message that it is the insulin regimen that is intensive rather than the management of the diabetes. Even when it is recognised that this is not the case (as discussed above), it is legitimate to ask what contribution is made by any particular regimen of insulin delivery to optimal blood glucose control within the context of intensive therapy.

As noted above, once daily insulin injection regimens were in general associated with very poor blood glucose control [2], but this was associated with a low level of intervention in nearly every other aspect. Accordingly, and in the absence of any satisfactory comparative trials of once daily compared to multiple injection therapy, it is not strictly possible to make any comment as to the level of control attainable with once daily regimens. Nevertheless, on basic pharmacokinetic principles, and in particular with modern porcine and human insulin preparations, it is unrealistic to expect that satisfactory blood glucose control can be achieved with such regimens [17], however intensive the other aspects of management.

Under very intensive conditions, no differences can be found in achieved control (including experience of hypoglycaemia) between subcutaneous infusion regimens and multiple injection therapy [9]. Some studies did find a difference, but in this case the particular choice of basal insulin preparation (bovine ultralente) almost certainly contributed to the poorer control found on the multiple injection regimen $[10,18]$. Attempts to ask whether continuous subcutaneous insulin-infusion might perform better in the context of more realistic (less intensive) diabetes management failed to find any differences in overall blood glucose control, as measured by glycated haemoglobin concentration [19].

Around that time a series of studies were performed in Newcastle upon Tyne using different insu- 
Table 2. Glycated haemoglobin concentrations (DCCT standardized) in four studies of insulin regimens in insulin-dependent diabetes

\begin{tabular}{llll}
\hline Reference & Insulin preparations & $\begin{array}{l}\text { Injection fre- } \\
\text { quency }\left(\text { day }^{-1}\right)\end{array}$ & $\begin{array}{l}\mathrm{HbA}_{1 \mathrm{c}} \\
(\% \mathrm{Hb})\end{array}$ \\
\hline 19 & $\begin{array}{l}\text { Continuous subcutaneous } \\
\text { insulin infusion }\end{array}$ & - & $7.4 \pm 0.4$ \\
& Unmodified $^{\mathrm{a}}+\mathrm{NPH}$ & 2 & $7.2 \pm 0.3$ \\
20 & Unmodified + lente $^{*}$ & 2 & $7.4 \pm 0.1$ \\
& Unmodified + NPH & 2 & $7.4 \pm 0.1$ \\
21 & Unmodified + lente & 2 & $7.4 \pm 0.1$ \\
\multirow{2}{*}{$\begin{array}{l}\text { unpub- } \\
\text { lished }\end{array}$} & Unmodified + ultralente & 2 & $7.4 \pm 0.1$ \\
\hline
\end{tabular}

Data are mean \pm SEM

a Soluble, regular

lin regimens (intensive, pump, pen-injector, different extended-acting insulin preparations), many of them using the same patients or pool of patients $[20,21]$. The blood glucose control achieved in those studies was measured by glycated haemoglobin concentration as $\mathrm{HbA}_{1}$, and when normalized to the DCCT $\mathrm{HbA}_{1 \mathrm{c}}$ assay the average results translate as $7.4 \%$ $\mathrm{Hb}$, just a little higher than the $7.1 \% \mathrm{Hb}$ achieved in that more intensive study. Remarkably however, the results achieved in Newcastle were nearly independent of the insulin regimen or method of insulin administration studied (Table 2), suggesting that insulin regimen (within the limits of those studied) was not a major factor in the blood glucose control achieved by intensive therapy.

Similar results have been reported from elsewhere, notably in regard to the control achieved by Danish children on multiple injection regimens [22]. This was a population, not a randomized, study, but one might have expected a bias in favour of more enthusiastic units both utilizing multiple injection therapy and having the knowledge and energy to achieve better blood glucose control.

Some caution is however required here; nearly all these studies used glycated haemoglobin as a measure of blood glucose control, and this is an averaging function not only over many days, but also between different times of day. This was most notable in the study of Marshall and colleagues [19], in which glycated haemoglobin concentration between injection therapy and pump therapy was not different, as discussed above. However, fasting blood glucose concentrations were lower on pump therapy, suggesting that glucose levels must have been higher at some other time of the day or night. A clue to this was the strong negative correlation between fasting blood glucose levels and glycated haemoglobin concentration in the patients on injection therapy, perhaps implying that hyperinsulinaemia in the early part of the night caused hypoglycaemia for an extended period, before insulin delivery waned and resulted in prebreakfast hyperglycaemia [23].

More recently short-acting insulin analogues have been tested in people with diabetes. Pre-clinical studies have quite clearly demonstrated the difference in pharmacokinetics between these analogues and native human insulin [24], and given the inappropriate profile of absorption of the latter [25], most authorities expected that clinical benefit would be relatively easy to demonstrate. In practice this has not proved to be the case, and, in the earlier blinded studies, insulin profiles have shown the expected advantage towards more physiological delivery, but blood glucose profiles have not been significantly improved [26]. Only with more rigorous control of insulin dose adjustment according to pre-determined algorithms has the benefit of short-acting analogues been recently demonstrable [27].

For the time being then, it must be concluded that insulin regimen (2-4 injections per day, or pumps), or insulin preparation (choice of extended-acting formulation, insulin species, or analogue), are not major components per se in the implementation of intensive insulin therapy.

\section{Insulin absorption or patient behaviour?}

The lack of feedback control of insulin delivery according to blood glucose levels (and other aspects of intermediary metabolism) is generally understood to be an important factor in the inability of (prospective) injections of insulin to achieve optimal blood glucose control [28]. However, for this to be a real problem it also has to be the case that serum insulin profiles after injection are unphysiological to an extent that human behaviour cannot adapt in order to match feeding patterns and physical exercise to the insulin delivery experienced. While the measured insulin profiles are indeed unphysiological [26, 29], the glucose profiles experienced by many people with diabetes are extraordinarily erratic, it not being at all unusual for the $95 \%$ range at any one time of day over the course of a month to be in the order of 2.5 to $14.0 \mathrm{mmol} \mathrm{l}^{-1}$. Such discrepancies are not easily explainable on the basis of median insulin profiles alone, and lead to the conclusion that either insulin absorption is very erratic, or that patient behaviour (feeding pattern, physical activity, or insulin injection) is very erratic, or both.

Insulin absorption has been known to be highly irreproducible since the time that insulin disappearance from subcutaneous tissue became measurable [30], and direct measurement of insulin profiles in both diabetic and non-diabetic humans confirms an effect both within a single profile, and between profiles [31, 32]. That erratic insulin absorption is a major contributor to the difficulty in achieving satisfactory 
blood glucose control is suggested, at least for the extended-acting insulin preparations, by the observation that the coefficient of variation of pre-breakfast blood glucose levels within individuals is similar to that at other times of day (when patient behaviour would be expected to have a much greater effect) [33]. This hypothesis has the interesting corollary that multiple, overlapping injections of insulin (say eight per day of unmodified insulin or four per day of extended-acting insulin) would smooth the unpredictable effect of erratic absorption from a single site, and thus improve blood glucose control. This has yet to be satisfactorily tested.

However, there can also be little doubt that the unpredictable nature of human behaviour also contributes to erratic blood glucose levels, through a failure of matching of insulin need to current insulin absorption. Aside from the anecdotal reports of people with diabetes, who are often able to explain large excursions in their measured blood glucose levels, it has been reported that certain groups of people have unfortunately used multiple injection regimens to free themselves from some of their previous restrictions on eating patterns, with resulting weight gain and worsening of blood glucose control [34].

\section{L essons for implementation of the intensive use of insulin therapy}

The results and observations discussed above suggest a number of practical lessons for the achievement of optimal blood glucose control in regular clinical practice:

1. Levels of blood glucose control comparable with those reported in the DCCT will not be achievable for any population-based cohort of people with insulin-dependent diabetes in the long-term, unless other means of motivation or self-discipline are found. Nevertheless less intense studies achieve mean glycated haemoglobin levels of around $7.4 \% \mathrm{Hb}\left(\mathrm{HbA}_{1 \mathrm{c}}\right.$, DCCT standardized) [20,21], while the normal clinic median in our own service is around $7.9-8.0 \% \mathrm{Hb}$, varying slightly year by year.

2. The chosen insulin regimen (number of injections per day) is of less importance than the skills of the patient and professional in adapting that regimen to personal circumstances. This is not to undervalue the importance to some people of multiple injection regimens in improving quality of life through the increase in flexibility that can be obtained.

3. Education of people with diabetes in regard to insulin therapy must seek to deliver not only the appropriate skills necessary for the optimal use of insulin therapy (such as self-monitoring and insulin dose adjustment), but also the ability to help such people attain their chosen blood control targets. This implies professional skills in personal motivation, still not adequately taught during post-graduate medical training. It seems unlikely that personal motivation will be enhanced by formal education programmes, but it is possible that the peer example effects of group discussions might be valuable.

4. In terms of blood glucose control (rather than immediate quality of life) the use of tools such as blood glucose rather than urine glucose monitoring is of less importance than making consistent use of the information through the setting of targets, and the repeated use of both patient and professional skills with the aim of moving ever closer to those targets without causing problems through hypoglycaemia. Unfortunately the optimum interval for obtaining professional advice remains untested. Self-monitored results and targets need to be audited against glycated haemoglobin levels, given the problems of accuracy and selection that the former can suffer [35, 36].

5. Hypoglycaemia will remain a problem for the majority of people with insulin-dependent diabetes where optimal blood glucose control is attempted. The acceptable frequency and extent of hypoglycaemia is a matter of personal informed choice, made in the knowledge of the risk and dangers of a severe event, and the balance of longer-term problems if blood glucose control is less good. Assisting patients with problematic hypoglycaemia requires a detailed understanding of insulin absorption profiles, as well as an ability to understand the influence of lifestyle.

\section{The future}

Given that human behaviour seems unlikely to change significantly, the effectiveness of insulin therapy is most likely to be enhanced by improvements in insulin delivery, and in particular an improvement in the reproducibility of insulin absorption from dayto-day. The problems in achieving this are underlined, as noted above, by the difficulty in demonstrating the advantage of the newer 'more physiological' insulin analogues [26]. Unfortunately it does appear that poorer bioavailability of injected insulin (a property associated with erratic absorption), correlates with time of residence in subcutaneous tissue, thus accounting for the poor performance of bovine ultralente and the failure of newer longer-acting insulin preparations [18, 37]. Caution is therefore advised in this respect with regard to slowly absorbed insulin analogues, or the newer fatty acid-linked albuminbinding preparations $[38,39]$.

Ultimately it is only the restoration of minute-tominute insulin delivery that can solve this problem. 
Chemical and physical engineering have made little practical progress in this regard over the past 20 years [40]. Can genetic engineering [41-42] do any better?

\section{References}

1. Pickup JC, Keen H, Parsons JA, Alberti KGMM (1978) Continuous subcutaneous insulin infusion: an approach to achieving normoglycaemia. BMJ i:204-207

2. Tamborlane WV, Sherwin RS, Genel M, Felig P (1979) Reduction to normal of plasma glucose in juvenile diabetes by subcutaneous administration of insulin with a portable pump. $\mathbf{N}$ Engl $\mathbf{J}$ Med 300: $573-578$

3. Johnsson S (1960) Retinopathy and nephropathy in diabetes mellitus: comparison of the effect of two forms of treatment. Diabetes 9: $1-8$

4. Walford S, Gale EAM, Allison SP (1978) Self monitoring of blood glucose. Lancet I:732-735

5. Sönksen PH, Judd SL, Lowy C (1978) Home monitoring of blood glucose. Lancet I:729-731

6. Jovanic L, Petersen CM (1981) The clinical utility of glycosylated haemoglobin. Am J Med 70: 331-338

7. McCulloch DK, Mitchell RD, Ambler J, Tattersall RB (1983) Influence of imaginative teaching on diet compliance and metabolic control in insulin-dependent diabetes. BMJ 287: 1858

8. Turner RC, Ward EA, Phillips MA, Dornan TL, Ward GM, Hockaday TDR (1979) Continuous subcutaneous insulin infusion or subcutaneous insulin injections. Lancet II:481 (Letter)

9. Reeves ML, Seigler DE, Ryan EA, Skyler JS (1982) Glycemic control in insulin-dependent diabetes mellitus: comparison of out-patient intensified conventional therapy with continuous subcutaneous insulin infusion. Am J Med 72: 673-680

10. Home PD, Capaldo B, Burrin JM, Worth R, Alberti KGMM (1982) A crossover comparison of continuous subcutaneous insulin infusion (CSII) against multiple insulin injections in insulin-dependent diabetic patients: improved control with CSII. Diabetes Care 5: 466-471

11. Calabrese G, Bueti A, Santeusanio F et al. (1982) Continuous subcutaneous insulin infusion treatment in insulin-dependent diabetic patients: a comparison with conventional optimized treatment in a long term study. Diabetes Care 5: 457-465

12. Worth R, Home PD, Johnston DG et al. (1982) Intensive attention improves glycaemic control in insulin dependent diabetes without further advantage from home blood glucose monitoring: results of a controlled trial. BMJ 285: 1233-1240

13. The DCCT Research Group (1993) The diabetes control and complications trial (DCCT): The effect of intensive diabetes treatment on long-term complications in IDDM. N Engl J Med 329: 977-986

14. Wang PH, Lau J, Chalmers TC (1993) Meta-analysis of effects of intensive blood-glucose control on late complications of type 1 diabetes. Lancet 341: 1306-1309

15. Reichard P, Bengt-Yngve N, Rosenquist U (1993) The effect of long-term intensified insulin treatment on the development of microvascular complication of diabetes mellitus. N Engl J Med 329: 304-309

16. DCCT Research Group (1986) The diabetes control and complications trial (DCCT): design and methodologic considerations for the feasibility phase. Diabetes 35: 530-545

17. Home PD, Alberti KGMM (1992) Insulin therapy. In: Alberti KGMM, DeFronzo RA, Keen H, Zimmet P (eds) International textbook of diabetes mellitus. John Wiley, Chichester pp 831-863

18. Home PD, Hanning I, Capaldo B, Alberti KGMM (1983) Bioavailability of highly purified bovine ultralente insulin. Diabetes Care 6: 210 (Letter)

19. Marshall SM, Home PD, Taylor R, Alberti KGMM (1987) Continuous subcutaneous insulin infusion versus injection therapy: a randomized cross-over trial under usual diabetic clinic conditions. Diabetic Med 4: 521-525

20. Tunbridge FKE, Newens A, Home PD et al. (1989) A comparison of human ultralente- and lente-based twice daily injection regimens. Diabet Med 6: 496-501
21. Tunbridge FKE, Newens A, Home PD et al. (1989) Double-blind cross-over trial of isophane (NPH)- and lente-based insulin regimens. Diabetes Care 12: 115-119

22. Mortensen HB, Hartling SG, Petersen KE, for the Danish Study Group of Diabetes in Childhood (1988) A nation-wide cross-sectional study of glycosylated haemoglobin in Danish children with type 1 diabetes. Diabet Med 5: 871-876

23. Gale EAM, Kurtz A, Tattersall RB (1980) In search of the Somogyi effect. Lancet II:1333-1334

24. Brange J, Owens DR, Kang S, Vølund A (1990) Monomeric insulins and their experimental and clinical implications. Diabetes Care 13: 923-954

25. Home PD, Shepherd GAA, Noy G et al. (1983) Comparison of the activity and pharmacokinetics of porcine insulin and human insulin (NOVO) as assessed by the glucose clamp technique in normal diabetic man. Diabetes Care 6 [Suppl 1]:23-28

26. Nielsen FS, Jørgensen LN, Ipsen M, Voldsgaard AI, Parving H-H (1995) Long-term comparison of human insulin analogue B10Asp and soluble human insulin in IDDM patients on a basal/bolus insulin regimen. Diabetologia 38: 592-598

27. Round PM, Olsen KJ, Home PD (1996) Improved blood glucose control with insulin analogue B28-Asp. Diabetologia 39[Suppl 1]:A24 (Abstract)

28. Alberti KGMM (1981) Insulin treatment and diabetes: half a century of therapeutic misadventure? In: Tunbridge WMG (ed) Advanced medicine. Pitman, Bath, pp 1-13

29. Home PD, Capaldo B, Alberti KGMM (1982) The quality of metabolic control during open-loop insulin infusion in type 1 diabetics. In: Mngola E (ed) Diabetes. Excerpta Medica, Amsterdam, pp 295-301

30. Lauritzen T, Pramming S, Gale E, Deckert T, Binder C (1982) Absorption of isophane (NPH) insulin and its clinical implications. BMJ 285: 159-162

31. Home PD, Pickup JC, Keen H, Alberti KGMM, Parsons JA, Binder C (1981) Continuous subcutaneous insulin infusion: comparison of plasma insulin profiles after infusion or bolus injection of the mealtime dose. Metabolism 30: 439-442

32. Home PD, Massi-Benedetti M, Gill GV, Capaldo B, Shepherd GAA, Alberti KGMM (1982) Impaired subcutaneous absorption of insulin in 'brittle' diabetics. Acta Endocrinologica 101: 414-420

33. Home PD, Thow JC, Tunbridge FKE (1989) Insulin treatment: a decade of change. Br Med Bull 45: 92-110

34. Hardy KJ, Jones KE, Gill GV (1991) Deterioration in blood glucose control in females with diabetes changed to a basal-bolus regimen using a pen-injector. Diabet Med 8: 69-71

35. Mazze RS, Shamoon H, Pasmantier R et al. (1984) Reliability of blood glucose monitoring by patients with diabetes mellitus. Am J Med 77: 211-217

36. Williams CD, Scobie IN, Till S, Crane R, Lowy C, Sonksen PH (1988) Use of memory meters to measure reliability of self blood glucose monitoring. Diabet Med 5: 459-462

37. Holman RR, Steemson J (1989) OPID 174: a novel long-acting insulin preparation. Diabet Med 6[Suppl 1]:A41 (Abstract)

38. Markussen J, Havelund S, Kurtzhals P, Andersen AS, Halstrøm J, Hasselager E et al. (1996) Soluble fatty acid acylated insulins bind to albumin and show protracted action in pigs. Diabetologia 39:281-288

39. Myers S, Yakabu-Madus F, Johnson W et al. (1995) W99-S32: a soluble, basal insulin analogue. Diabetologia 38[Suppl 1]:A4. (Abstract)

40. Reach G (1993) Continuous glucose monitoring with a subcutaneous sensor: rationale, requirements and achievements, and prospects. In: Marshall SM, Home PD, Alberti KGMM, Krall L (eds) The diabetes annual/7. Elsevier, Amsterdam, pp 332-348

41. Selden RF, Skoskeiwicz MJ, Russell PS, Goodman HM (1987) Regulation of insulin gene expression. Implications for gene therapy. N Engl J Med 317: 1067-1076

42. Bailey CJ, Docherty K (1994) Exploring the feasibility of insulin gene therapy. In: Flatt PR, Lenzen S (eds) Frontiers of insulin secretion and pancreatic B cell research. Smith-Gordon, London, pp 613-620 